\title{
Enhancement of Reporter-Gene Expression by Insertions of Two Introns in Maize and Tobacco Protoplasts
}

\author{
Jun Ueki ${ }^{1 *}$, Toshihiko Komari ${ }^{1}$ and Hidemasa Imaseki ${ }^{2}$

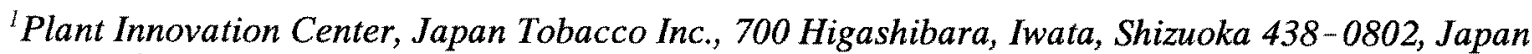 \\ ${ }^{2}$ Nagoya University, 2-4-19 Obata-minami, Moriyama, Nagoya 463-0048, Japan \\ *Corresponding author E-mail address: jun.ueki@ims.jti.co.jp
}

Received 23 July 2003; accepted 12 September 2003

\begin{abstract}
The effects of two-intron insertions on reporter-gene expression were examined in transient assays in maize and tobacco. The first introns of a rice gene for phospholipase D (PLD), a maize gene for ubiquitin and a castor bean gene for catalase were tested with a gene for $\beta$-glucuronidase (GUS) or a gene for luciferase driven by a cauliflower mosaic virus $35 \mathrm{~S}$ promoter (35S-GUS or $35 \mathrm{~S}-\mathrm{Luc}$ ), the promoter of the maize ubiquitin (Ubi-GUS) or the promoter of a maize pyruvate, orthophosphate dikinase (PPDK-GUS). Although the enhancing effect varied, several intron combinations synergistically enhanced the reporters. When the first and second introns of the PLD gene were inserted in tandem, the reporter was synergistically enhanced. These results imply that expression enhancement by two introns may be observed in wide combinations of promoters, introns, and structural genes and that such enhancement plays certain roles in regulation of gene expression in higher plants.
\end{abstract}

Key words: Expression enhancement, Gene expression, Intron, Maize (Zea mays), Protoplast, Tobacco (Nicotiana tabacum).

\section{Abbreviations}

CaMV, cauliflower mosaic virus; Cat, catalase; Cat-int1, first intron of a castor bean gene for catalase; GUS, $\beta$-glucuronidase; Luc, luciferase; Nos, a gene for nopaline synthase; PLD, phospholipase D; PLD-int1 or 2, first or second intron of a rice gene for phospholipase D; PPDK, pyruvate, orthophosphate dikinase; SI, synergy index; Ubi, ubiquitin; Ubi-int1, first intron of a maize gene for ubiquitin.

\section{Introduction}

The enhancement of gene expression by introns has been reported for many plant and animal genes. The effects of introns, mainly the first introns, have been tested by their removal from a native sequence or insertion between a promoter and a reporter gene in transient or stable transformation assays. In plant genes, the first introns of maize genes for alcohol dehydrogenase-1 (Adh1) and UDP-glucose 3-Oglucosyl transferase $(b z 1)$ were first reported to increase gene expression (Callis et al., 1987), followed by the first introns of genes for maize sucrose synthase (Vasil et al., 1989), rice actin (McElroy et al., 1990) and castor bean catalase (Tanaka et al., 1990). More than twenty introns have been reported to increase gene expression. The enhancing effect of introns is generally higher in monocotyledons than in dicotyledons. The range of enhancement reported is roughly 2-5 fold for dicotyledons and 10-100 fold for monocotyledons (Simpson and Filipowicz, 1996). The use of introns with the adjacent exon segments resulted in even stronger expression in monocotyledons (Mascarenhas et al., 1990; Maas et al., 1991).

Despite the dramatic effect of introns, the mechanism of intron-mediated enhancement of gene expression is not well understood. The degree of enhancement depends on many factors such as the intron used, its location in the transcript, the nature of other sequences in the construct (such as the promoter and exon sequences), the cell type in which expression takes place and the physiological status of those cells (Simpson and Filipowicz, 1996). Furthermore, expression enhancement by an intron was shown to be a process dependent on structural genes (Rethmeier et al., 1997). This phenomenon is associated with an increase in the steady-state level of the mRNA, and several lines 
of evidence indicate that introns act post-transcriptionally (Dean et al., 1989; Huang and Gorman, 1990; Rose and Last, 1997). The deletion of internal sequences in introns still retained intron-mediated enhancement (Mascarenhas et al., 1990; Clancy et al., 1994; Luehrsen and Walbot, 1994; Rose and Beliakoff, 2000), which may explain that certain sequences of introns are redundant (Luehrsen and Walbot, 1994) or that most intron sequences are dispensable (Rose and Beliakoff, 2000). The correlation between efficient splicing and intron-mediated enhancement was pointed out (Tanaka et al., 1990; Luehrsen and Walbot, 1994), while an opposite case that splicing is unnecessary for enhancement was reported (Rose and Beliakoff, 2000). Export of mRNA is said to be coupled to premRNA splicing (Reed and Hurt, 2002), so the interaction between pre-mRNA and mRNA export machinery, even if not spliced, might be the key to an efficient export of mRNA from the nucleus to the cytoplasm.

Several genes are known to require an intron for expression at proper levels (Callis et al., 1987; Dean et al., 1989; McElroy et al., 1990; Curie et al., 1993; Norris et al., 1993; Xu et al., 1994; Donath et al., 1995; Rose and Last, 1997). An Arabidopsis gene for ribosomal protein kinase (atpk1) is expressed in all tissues, but the expression is restricted to cotyledon tips without the intron (Zhang et al., 1994). Removal of the first intron from a potato gene for sucrose synthase (Sus4) changed the location of expression in the root tips from the root cap and apical meristem to the procambium (Fu et al., 1995). Tissue-preferential expression of a rice gene for $\alpha$-tubulin (OsTubA1) is mediated by the first intron, where the intron is necessary for the normal expression in actively dividing tissues (Jeon et al., 2000). These studies have shown the evidence that introns play regulatory roles in plant gene expression.

On the practical side, this phenomenon is very useful for obtaining a high expression level of a transgene (Maruta et al., 2001), and the technique for higher expression level with introns is required for the improvement of useful plants. The effect of intron insertions has been studied mainly with single-intron insertions, and the limited trials of inserting two introns in tandem had resulted in less than additive effects (Mascarenhas et al., 1990; Luehrsen and Walbot, 1991; Clancy et al., 1994). Previously, we reported that the insertion of two introns in tandem synergistically enhanced the expression of GUS gene driven by the $35 \mathrm{~S}$ promoter in rice protoplasts, and that the enhancement was accompanied by an increase in the steady-state level of the transcript (Ueki et al., 1999). Here, we describe the effect of two-intron insertions on reporter-gene expression using chimeric genes of various combinations of promoters, introns and structural genes in maize and tobacco protoplasts.

\section{Materials and Methods}

\section{Construction of chimeric genes}

DNA manipulations were carried out by the standard techniques (Sambrook et al., 1989). Unless otherwise mentioned, DNA fragments were bluntended with a Klenow fragment when the ligation of DNA fragments with incompatible ends was carried out.

\section{CaMV 35 S promoter and GUS}

$35 \mathrm{~S}-$ GUS reporters with either one or two of the first introns of a rice gene for phospholipase D (PLD-int1), a maize gene for ubiquitin (Ubi-int1) and a castor bean gene for catalase (Cat-int1) were constructed as described in our previous study (Ueki et al., 1999).

\section{Ubiquitin promoter and GUS}

A region that contained the promoter, $5^{\prime}$-exon and first intron (Ubi-int1) of a maize gene for ubiquitin, Ubi-1 (Christensen et al., 1992), was excised with PstI and subcloned in pUC18. The promoter region excised with $H$ indIII and $B g l I I$ was inserted between the HindIII and XbaI sites of pBI221 (Jefferson, 1987), pBI[PLD] (Ueki et al., 1999) and pIG221 (Ohta et al., 1990) to yield pUQ, pUQ[PLD] and pUQ[Cat], respectively. The intron fragment excised with $B g l \mathrm{II}$ and $B a m \mathrm{HI}$ was inserted at the SmaI sites of pUQ and pUQ[PLD] to yield pUQ[Ubi] and pUQ[PLD/Ubi], respectively. pUQ[PLD] was digested with HindIII and BglII, and the resultant fragment was inserted between the HindIII and BglII sites of pIG[PLD/Cat] to yield pUQ[PLD/Cat]. The promoter region with the intron was excised with HindIII and BamHI, and inserted between the HindIII and XbaI sites of pIG221 to yield pUQ[Ubi/Cat]. In plasmids that contain the Cat intron (Cat-int1), splicing is required for the expression of GUS activity (Ohta $e t$ al., 1990).

\section{$P P D K$ promoter and GUS}

A $1.0 \mathrm{~kb}$ DNA fragment that contained a promoter region of a maize gene for PPDK was prepared by PCR with genomic DNA from maize cultivar B73 as template. The amplified fragment was subcloned into PCR1000 vector (Invitrogen), excised with SacI, blunt-ended with T4 DNA 
polymerase, and then subcloned at the SmaI site of pUC119. The promoter region excised with HindIII and EcoRI was inserted between the HindIII and $X b a I$ sites of pBI221, pBI[PLD], and pIG221 to yield pDK, pDK[PLD], and pDK[Cat], respectively. The intron fragment for ubiquitin excised with $B g l \mathrm{II}$ and BamHI was inserted at the SmaI sites of pDK and pDK[PLD] to yield pDK[Ubi] and pDK[PLD/Ubi], respectively. This intron fragment was also inserted at the $X b a I$ site of pDK[Cat] to yield pDK[Ubi/Cat]. A fragment excised with HindIII and $B g l \mathrm{II}$ from pDK[PLD] was inserted between the HindIII and $B g l \mathrm{II}$ sites of $\mathrm{pIG}[\mathrm{PLD} / \mathrm{Cat}]$ to yield pDK[PLD/Cat]. In plasmids that contain Cat intron, splicing is required for the expression of GUS activity (Ohta et al., 1990).

\section{CaMV 35 promoter and luciferase}

A fragment containing the coding region of a gene for firefly luciferase was excised with $\mathrm{BamHI}$ and SacI from pDO432 (Ow et al., 1986), inserted between the BamHI and SacI sites of pUC19, and excised with $S m a I$ and $S a c I$. The fragment was inserted at the SmaI sites of pBI221, pBI[PLD] and $\mathrm{pBI}[\mathrm{Ubi}]$, to yield p35Luc, p35Luc[PLD] and p35Luc[Ubi], respectively. The intron fragment for catalase that had been excised with BamHI and SalI from pIG221 was inserted at the SmaI sites of p35Luc, p35Luc[PLD] and p35Luc[Ubi] to yield p35Luc[Cat], $\mathrm{p} 35 \mathrm{Luc}[\mathrm{PLD} / \mathrm{Cat}]$ and $\mathrm{p} 35 \mathrm{Luc}[\mathrm{Ubi} / \mathrm{Cat}$, respectively. Because the Cat intron was inserted in the $5^{\prime}$ untranslated region, splicing is not required for the expression of GUS activity. The intron fragment for ubiquitin excised with $B g l \mathrm{II}$ and BamHI was inserted at the SmaI site of p35Luc[PLD] to yield p35Luc[PLD/Ubi].

PLD or CaMV $35 S$ promoter, PLD intron $1 \& 2$, and GUS

A promoter fragment, the first intron (PLD-int1) and the 2nd intron (PLD-int2) from PLD1 (Morioka et al., 1997) were prepared by PCR. Primers used were 5'-GTCCAACTTAAGCTTCTTCAGTCATTTTCC- $3^{\prime}$ and $3^{\prime}$-GGGCGTTAAAATATTCCTAGGGCCCAGTAT $-5^{\prime}$ for the PLD promoter, 5 -AGTCAGGGATCCCCCGGAGAAGACGCC TCC- $3^{\prime}$ and $3^{\prime}$-GTTTAGGTTTAGTCGTCGG CCTAGGCAGAC-5' for PLD int1, 5'-AAGTC CCCCGGGCCGCGCCAGCGGAAG-3' and 3'GACACCCACAGCCGTCTATAGTTCGTA-5' for PLD int2. The amplified fragments were subcloned into pCRII (Invitrogen, San Diego, CA, USA). The PLD promoter fragment excised with HindIII and BamHI were inserted between the HindIII and Bam HI sites of pBI221 (pLDpro). The PLD-int1 fragment excised with BamHI and PLD-int2 fragment excised with $S m a \mathrm{I}$ and $E c o$ RV were inserted into the BamHI site and SmaI site of pLDpro, respectively, (pLDpro[1st] and pLDpro[2nd]). The PLD-int1 fragment excised with BamHI was inserted into the BamHI site of pLDpro[2nd] to yield pLDpro[1st /2nd]. Because the length between the 3 splicing site of the PLD-int1 and the translation initiation site was 37 bases in the native gene for PLD, both intron fragments were flanked by 37 bases each of the exon sequences at both ends. The PLD-int 1 fragment flanked by 10 bases each of the exon sequences at both ends is described "PLD" in plasmid names as was the case in the previous study (Ueki et al., 1999).

The PLD-int1 fragment excised with Bam HI and the PLD-int2 fragment excised with SmaI and $E c o$ RV were inserted into the BamHI site and SmaI site of pBI221, respectively (pBI[1st] and pBI[2nd]). The PLD-int1 fragment excised with $B a m H I$ was inserted into the BamHI site of $\mathrm{pBI}[2 \mathrm{nd}]$ to yield $\mathrm{pBI}[1 \mathrm{st} / 2 \mathrm{nd}]$.

\section{Protoplast isolation, electroporation and analysis of reporter-gene expression}

Seed line, growth conditions, and protoplast isolation of maize were as described by Sheen (Sheen, 1991). Protoplasts were isolated from etiolated leaves (yellow protoplasts) and greening leaves under room light for $17 \mathrm{~h}$ (greening protoplasts) of maize plants at 10 days after germination, then suspended in electroporation buffer, namely, $0.6 \mathrm{M}$ mannitol and $20 \mathrm{mM} \mathrm{KCl}$ in $4 \mathrm{mM}$ Mes- $\mathrm{NaOH}, \mathrm{pH}$ 5.7 (Sheen, 1991). Electroporation was carried out with $30 \mu \mathrm{g}$ of plasmid DNA which contained a gene for GUS, $15 \mu \mathrm{g}$ of pDO432 (Ow et al., 1986) which contained a gene for luciferase, $75 \mu \mathrm{g}$ of salmon sperm DNA, and $1 \times 10^{5}$ protoplasts in $0.8 \mathrm{ml}$ of electroporation buffer at $125 \mu \mathrm{F}$ and $400 \mathrm{~V} \mathrm{~cm}^{-1}$ with one pulse, in a Bio-Rad Gene Pulser (Hercules, CA, USA). After electroporation, protoplasts derived from etiolated or greening leaves were incubated for $16 \mathrm{~h}$ at $25^{\circ} \mathrm{C}$ in darkness or under white light $\left(20 \mu \mathrm{E} \mathrm{m}^{-2}\right)$, respectively.

Tobacco suspension culture (BY-2) and green leaves (BY-4) were digested for 3 and $16 \mathrm{~h}$, respectively, at $25^{\circ} \mathrm{C}$ in darkness with the same solution used for the digestion of maize leaves. Protoplasts isolated from cultured cells (white protoplasts) and green leaves (green protoplasts) were suspended in electroporation buffer, and electroporation was carried out as described above except for the pulse condition at $125 \mu \mathrm{F}$ and $500 \mathrm{~V} \mathrm{~cm}^{-1}$. After electroporation, protoplasts derived from the suspension culture and leaves were incubated for $16 \mathrm{~h}$ at $25^{\circ} \mathrm{C}$ 
1in darkness or under white light, respectively.

Protoplasts were suspended in $75 \mu 1$ of $50 \mathrm{mM}$ Tirs $-\mathrm{H}_{3} \mathrm{PO}_{4}, \mathrm{pH}$ 7.5. After addition of $75 \mu \mathrm{l}$ of Lysis Reagent Luc (Toyo Ink MFG., Tokyo, Japan), the mixture was sonicated three times for $10 \mathrm{~s}$ with $10 \mathrm{~s}$ intervals. Assays of GUS activity were performed as described by Jefferson (Jefferson, 1987). Assays of luciferase activity were performed with PicaGene (Toyo Ink MFG.). GUS activity was normalized by luciferase activity obtained by cotransformation with the plasmid pDO432 (Ow et al., 1986).

Chimeric genes employing the same promoter were introduced to the protoplasts isolated in a single preparation, and the overall response shown as a single experiment here was confirmed with another experiment.

\section{Results}

Normalization of measurement of reporter genes activities

Because the expression level of a reporter gene usually varies considerably from experiment to another in transient assays, additional reporter gene was introduced into plant cells together as an internal control (Callis et al., 1987; Leckie et al., 1994; Kovtun et al., 1998). In a preliminary study, the plasmid pIG221, which contained a GUS gene driven by the CaMV $35 \mathrm{~S}$ promoter (35S-GUS), and the plasmid pDO432, which contained a luciferase gene driven by $35 \mathrm{~S}$ promoter $(35-\mathrm{Luc})$, were cointroduced into protoplasts isolated from etiolated maize leaves. The standard deviation of GUS activities from six independent experiments was 0.22 relative to the mean value. The ratio of the GUS activity and luciferase activity in each experiment was then taken as a normalized GUS activity. The standard deviation of the normalized GUS activities was 0.04 relative to the mean value. Therefore, the normalized activities were reasonably invariable over experiments. In this study, the luciferase construct was used as the internal control for all assays of GUS constructs and vice versa. Furthermore, because variations in measurements with a single preparation of protoplasts are usually smaller, even after normalization, than those with more than one preparations (Leckie et al., 1994), one set of constructs, which consisted of several constructs with the same promoter and various combinations of introns, were assayed with a single preparation of protoplasts throughout this study.

\section{Effect of introns in maize protoplasts}

The effect of introns on reporter-gene expression in maize protoplasts was examined with the chimeric genes that contain one or two introns between a promoter and a reporter gene (Fig. 1A). Values relative to the GUS activity obtained with an intron - less construct (pBI221, pUQ or pDK) are shown in Table 1. A drastic increase in expression of the GUS gene was brought by the insertion of introns, and the highest activity was obtained from one of the two-intron constructs for each promoter in both yellow and greening protoplasts.

For the evaluation of the effects of the two introns inserted in tandem, a synergy index (SI), defined as [enhancement by two introns in tandem]/[enhancement by one intron]+[enhancement by the other intron] was calculated (Table 1). An SI of 1.00 indicates that the effect is additive, and an SI greater than 1.00 indicate that the effect is synergistic.

Combinations of PLD-int1 and Ubi-int1 (abbreviated as PLD-int1/Ubi-int1) and PLD-int1/Catint1 synergistically enhanced the expression of the 35 S-GUS in both yellow and greening protoplasts (pBI[PLD/Ubi], pIG[PLD/Cat]). The effect of Ubiint1/Cat-int1 (pBI[Ubi/Cat]) was not much different from the single insertion of Ubi-int1 (pBI[Ubi]) in yellow protoplasts and was merely additive in greening protoplasts. Combinations of PLDint1/Cat-int 1 and Ubi-int1/Cat-int1 synergistically enhanced the expression of the Ubi-GUS in both yellow and greening protoplasts (pUQ[PLD/Cat], pUQ[Ubi/Cat]). The effect of PLD-int1/Ubi-int1 was synergistic only in greening protoplasts (pUQ[PLD/Ubi]). Combination of PLD-int1/Catint1 and Ubi-int1/Cat-int1 synergistically enhanced the expression of the PPDK-GUS in both yellow and greening protoplasts (pDK[PLD/Cat], pDK[PLD/Ubi]). Enhancement of the expression of PPDK - GUS by the single insertion of Ubi-int1 was relatively great, and the addition of PLD-int1 to the construct appeared to suppress the expression (pDK[PLD/Ubi]).

\section{Effect of introns in tobacco protoplasts}

The effect of introns on reporter-gene expression in tobacco protoplasts is also shown in Table 1. In general, the effect of introns on expression of the GUS gene was much less than that in maize protoplasts. Still, the effect of two-intron insertions was greater than that of single-intron insertions in most cases. Synergistic enhancement was clear in the expression of 35 -GUS with PLD-int1/Ubi-int1 in white and green protoplasts (pBI[PLD/Ubi]), and in the expression of PPDK-GUS with PLD-int1/Catint1 and PLD-int1/Ubi-int1 in white protoplasts (pDK[PLD/Cat], pDK[PLD/Ubi]). 


\begin{tabular}{|c|c|c|c|c|c|}
\hline 35S / Ubi / PPDK Promoter & & GUS / Luc & & Hos & \\
\hline 35S / Ubi / PPDK Promoter & Intron & & GUS/Luc & & HNos \\
\hline 35S / Ubi / PPDK Promoter & Intron 1 & Intron 2 & & GUS / Luc & \\
\hline
\end{tabular}

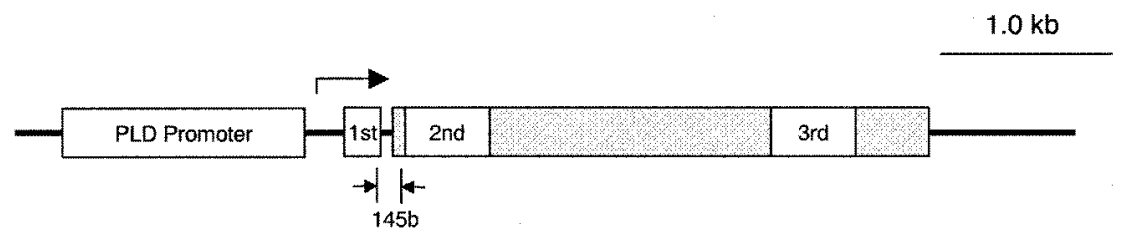

\begin{tabular}{|c|c|c|c|}
\hline PLD / 35S Promoter & GUS \\
\hline PLD / 35S Promoter
\end{tabular}

Fig. 1 Diagrams of genes. (A) Structure of chimeric genes with intron insertions. Promoters of genes for cauliflower mosaic virus, maize ubiquitin or maize pyruvate, orthophosphate dikinase were used to drive reporter genes. GUS and Luc indicate the coding regions of genes for $\beta$-glucuronidase and luciferase, respectively. Nos indicates the terminator of a gene for nopaline synthase. Introns were inserted between the promoter core and the coding sequence of GUS or Luc except that the first intron of castor bean catalase gene (Cat-int1) resides within the amino-terminal region of the GUS-coding sequence. (B) Structure of a rice gene for phosphplipase D (PLD1) and chimeric genes with PLD introns. Open boxes represent introns and stippled boxes represent the coding sequence of PLD. An arrow denotes the transcription start.

\section{Effect on another reporter gene in maize}

Because the intron-mediated enhancement of transgene expression was reported to be a genedependent process (Rethmeier et al., 1997), we tested another reporter gene, a gene for luciferase. As shown in Table 2, single insertions of PLDint1, Cat-int1 and Ubi-int1 had enhancing effects, and the effect of Ubi-int1 was the biggest (p35Luc[Ubi]) of the three. SI values greater than 1.0 were observed in the combination of PLDint1/Cat - int1 (p35Luc[PLD/cat]) in greening protoplasts in maize.
Effect of PLD introns on the expression of GUS gene driven by PLD or CaMV $35 S$ promoter

PLD1 is one of the PLD genes in rice, and it has three introns. The first (PLD-int1) and second (PLD-int2) are located very close to each other (Fig. 1B) (Morioka et al., 1997) in the 5' end of the transcribed region. It is possible that both of the introns are involved in regulation of the gene. A GUS gene construct, in which the structure of the $5^{\circ}$ end of PLD1 gene was mimicked, was made. Either the native promoter of $P L D 1$ or the CaMV $35 \mathrm{~S}$ promoter was connected to the gene. Under the control of the PLD1 promoter, single insertions of 
Table 1 Relative GUS activities compared to intron-less constructs in protoplasts and synergy. Plasmid pDO432 (35S-Luc) was co-transformed for the normalization of GUS activity. Yellow and greening refer to protoplasts isolated from maize etiolated leaves and greening leaves, respectively. White and green refer to protoplasts isolated from tobacco cultured cells and green leaves, respectively. A synergy index (SI), defined as [enhancement by two introns in tandem]/[enhancement by one intron]+[enhancement by the other intron], is given for each of chimeric genes that contained two introns.

\begin{tabular}{|c|c|c|c|c|c|c|c|c|c|c|c|}
\hline \multirow[t]{3}{*}{ Plasmid } & \multicolumn{5}{|c|}{ Structure of plasmid } & \multicolumn{6}{|c|}{ Relative activity } \\
\hline & \multirow{2}{*}{$\begin{array}{c}\text { Promo- } \\
\text { ter }\end{array}$} & \multirow{2}{*}{$\begin{array}{c}\text { ntron- } \\
1\end{array}$} & \multirow{2}{*}{$\begin{array}{c}\text { Intron- } \\
2\end{array}$} & \multirow{2}{*}{$\begin{array}{c}\text { Repor- } \\
\text { ter }\end{array}$} & \multirow{2}{*}{$\begin{array}{c}\text { Termi- } \\
\text { nator }\end{array}$} & \multicolumn{4}{|c|}{ Maize } & \multicolumn{2}{|c|}{ Tobacco } \\
\hline & & & & & & Yell & (SI) & Greer & $\begin{array}{l}\text { ing } \\
\text { (SI) }\end{array}$ & $\begin{array}{l}\text { White } \\
\text { (SI) }\end{array}$ & $\begin{array}{l}\text { Green } \\
\quad(\mathrm{SI})\end{array}$ \\
\hline pBI221 & $35 \mathrm{~S}$ & & & GUS & Nos & 1.00 & & 1.00 & & 1.00 & 1.00 \\
\hline pBI[PLD] & $35 \mathrm{~S}$ & PLD & & GUS & Nos & 7.36 & & 4.73 & & 3.61 & 2.85 \\
\hline pIG221 & $35 \mathrm{~S}$ & Cat & & GUS & Nos & 14.3 & & 14.6 & & 1.38 & 3.38 \\
\hline $\mathrm{pBI}[\mathrm{Ubi}]$ & $35 \mathrm{~S}$ & Ubi & & GUS & Nos & 47.6 & & 51.7 & & 1.39 & 1.40 \\
\hline pIG[PLD/Cat] & $35 \mathrm{~S}$ & PLD & Cat & GUS & Nos & 78.4 & (3.62) & 53.1 & (2.75) & $2.11(0.42)$ & $5.79(0.93)$ \\
\hline pBI[PLD/Ubi] & $35 \mathrm{~S}$ & PLD & Ubi & GUS & Nos & 97.8 & $(1.78)$ & 70.5 & (1.25) & $9.40(1.88)$ & $5.05(1.19)$ \\
\hline pIG[Ubi/Cat] & $35 \mathrm{~S}$ & Ubi & Cat & GUS & Nos & 50.1 & $(0.81)$ & 70.0 & $(1.05)$ & $1.38(0.50)$ & $2.27(0.47)$ \\
\hline pUQ & Ubi & & & GUS & Nos & 1.00 & & 1.00 & & 1.00 & 1.00 \\
\hline pUQ[PLD] & Ubi & PLD & & GUS & Nos & 3.66 & & 7.66 & & 0.64 & 1.39 \\
\hline pUQ[Cat] & Ubi & Cat & & GUS & Nos & 11.5 & & 53.0 & & 1.54 & 2.72 \\
\hline pUQ[Ubi] & Ubi & Ubi & & GUS & Nos & 34.2 & & 35.2 & & 2.26 & 2.55 \\
\hline pUQ[PLD/Cat] & Ubi & PLD & Cat & GUS & Nos & 18.3 & $(1.20)$ & 86.5 & (1.42) & $1.56(0.71)$ & $2.50(0.61)$ \\
\hline pUQ[PLD/Ubi] & Ubi & PLD & Ubi & GUS & Nos & 30.8 & $(0.81)$ & 100 & (2.35) & $2.54(0.88)$ & $2.49(0.63)$ \\
\hline pUQ[Ubi/Cat] & Ubi & Ubi & Cat & GUS & Nos & 78.7 & $(1.72)$ & 229 & $(2.60)$ & $2.76(0.73)$ & $2.30(0.44)$ \\
\hline pDK & PPDK & & & GUS & Nos & 1.00 & & 1.00 & & 1.00 & 1.00 \\
\hline pDK[PLD] & PPDK & PLD & & GUS & Nos & 3.42 & & 5.98 & & 0.82 & 1.22 \\
\hline pDK[Cat] & PPDK & Cat & & GUS & Nos & 2.52 & & 8.65 & & 0.93 & 2.57 \\
\hline pDK[Ubi] & PPDK & Ubi & & GUS & Nos & 193 & & 184 & & 2.48 & 3.78 \\
\hline pDK[PLD/Cat $]$ & PPDK & PLD & Cat & GUS & Nos & 7.29 & $(1.23)$ & 18.3 & (1.25) & $3.96(2.26)$ & $2.43(0.64)$ \\
\hline pDK[PLD/Ubi] & PPDK & PLD & Ubi & GUS & Nos & 75.9 & $(0.39)$ & 124 & $(0.65)$ & $4.14(1.25)$ & $3.59(0.72)$ \\
\hline pDK[Ubi/Cat] & PPDK & Ubi & Cat & GUS & Nos & 277 & (1.42) & 223 & (1.16) & $2.34(0.69)$ & $4.81(0.76)$ \\
\hline
\end{tabular}

Table 2 Relative Luc activities compared to the intron-less construct (p35Luc) in protoplasts and synergy index. Plasmid pBI221 (35S-GUS) was co-transformed for the normalization of Luc activity. Yellow and green refer to protoplasts isolated from young maize etiolated leaves and greening leaves, respectively. A synergy index (SI), defined in the legend of Table 1, was given for the constructs that contained two introns.

\begin{tabular}{lccccccc}
\hline \multicolumn{1}{c}{ Plasmid } & \multicolumn{3}{c}{ Structure of plasmid } & \multicolumn{2}{c}{ Relative activity } \\
\hline & Promoter & Intron1 & Intron2 & Reporter & Terminator & $\begin{array}{r}\text { Yellow } \\
\text { (SI) }\end{array}$ & $\begin{array}{r}\text { Greening } \\
\text { (SI) }\end{array}$ \\
\hline p35Luc & $35 \mathrm{~S}$ & & & Luc & Nos & 1.00 & 1.00 \\
p35Luc[PLD] & $35 \mathrm{~S}$ & PLD & & Luc & Nos & 15.3 & 7.70 \\
p35Luc[Cat] & $35 \mathrm{~S}$ & Cat & & Luc & Nos & 23.1 & 20.6 \\
p35Luc[Ubi] & $35 \mathrm{~S}$ & Ubi & & Luc & Nos & 110 & 51.4 \\
pIG[PLD/Cat] & $35 \mathrm{~S}$ & PLD & Cat & Luc & Nos & $39.2(1.02)$ & $32.5(1.15)$ \\
p35Luc[PLD/Ubi] & $35 S$ & PLD & Ubi & Luc & Nos & $61.1(0.48)$ & $56.5(0.96)$ \\
p35Luc[Ubi/Cat] & $35 S$ & Ubi & Cat & Luc & Nos & $59.5(0.44)$ & $44.5(0.62)$ \\
\hline
\end{tabular}


both of the introns had a small enhancing effect, and the combination of the two introns showed a very high SI value (3.22) (Table 3). Under the control of the CaMV $35 \mathrm{~S}$ promoter, the enhancement by a single insertion of PLD - int2 was very large, and no more enhancement was observed by the addition of the first intron.

\section{Discussion}

Our previous study demonstrated that the twointron insertions of certain combinations of introns synergistically enhanced the expression of the GUS gene driven by the CaMV $35 \mathrm{~S}$ promoter in rice protoplasts (Ueki et al., 1999). The introns used in the study were PLD-int1, Cat-int1, Ubi-int1 and the first intron (Skn-int1) of a maize Shrunken-1 gene. The combinations of PLD-int1/Cat-int1, PLD-int1/Ubi-int1, PLD-int1/Skn-int1, Ubiint1/Cat-int1 and Cat-int1/Skn-int1 had expression-enhancing effect in rice protoplasts isolated from cultured cells or greening leaves. Here, we described that the effects of two-intron insertions were evident also in maize and tobacco protoplasts. For each of the $35 \mathrm{~S}$ promoter, Ubi promoter, and PPDK promoter, certain combinations of two introns had an enhancing effect on reporter-gene expression in maize protoplasts isolated from both etiolated and greening leaves. When the structural gene was replaced with the luciferase gene, an additive effect was observed with the combination of PLD-int1/Cat-int1 in maize cells. Furthermore, the enhancing effect of two-intron insertions was also observed in tobacco protoplasts, although the effect was much smaller than that in maize proto- plasts. These results imply that expression enhancement by two introns may be observed in wide combinations of promoters, introns, and structural genes in plant cells.

Expression-enhancing effect of monocotyledonous introns in dicotyledonous protoplasts has not been reported. For example, the presence of Skn -int1 greatly reduced the reporter-gene expression in tobacco protoplasts (Maas et al., 1991). In addition to the enhancement by the single-intron insertions, certain two-intron insertions showed a synergistic effect in protoplasts isolated from tobacco. The fact that the combination of the monocotyledonous introns (PLD-int1/Ubi-int1) showed a synergistic enhancing effect on the expression of the GUS gene driven by the monocotyledonous promoter (PPDK) in tobacco cells suggests that certain regulatory elements derived from monocotyledonons may function effectively in cells of dicotyledonous plants. Expression enhancement by twointron insertions as well as by single-intron insertions was higher in maize cells than in tobacco cells. The enhancing effect is generally higher in monocotyledons than in dicotyledons, and the reasons for the difference remain to be elucidated. The machinery used for the processing of pre-mRNAs may be different in each plant species (Tanaka et al., 1990), particularly between monocotyledons and dicotyledons.

Until recently, the main focus in the studies of regulatory functions of introns in native plant genes had been in the first introns of genes, because they are located relatively close to the main regulatory elements, such as promoters. Our studies have shown that all of the combinations of introns tested

Table 3 Effect of PLD intron insertions of on the GUS gene expression in maize protoplasts. Relative GUS activities compared to intron-less constructs (pLDpro or pBI221) are shown. Plasmid pDO432 (35S-Luc) was co-transformed for the normalization of GUS activity. Protoplasts isolated from maize etiolated leaves were used. A synergy index (SI), defined in the legend of Table 1, was given for the constructs that contained two introns.

\begin{tabular}{lcccccc}
\hline \multicolumn{1}{c}{ Plasmid } & \multicolumn{3}{c}{ Structure of plasmid } & & Relative activity \\
\hline & Promoter & Intron1 & Intron2 & Reporter & Terminator & (SI) \\
\hline pLDpro & PLD & & & GUS & Nos & 1.00 \\
pLDpro[1st] & PLD & PLD-int1 & & GUS & Nos & 1.31 \\
pLDpro[2nd] & PLD & PLD-int2 & & GUS & Nos & 1.89 \\
pLDpro[1st/2nd] & PLD & PLD-int1 & PLD-int2 & GUS & Nos & $10.3(3.22)$ \\
pBI221 & 35S & & & GUS & Nos & 1.00 \\
pBI[1st] & 35S & PLD-int1 & & GUS & Nos & 3.78 \\
pBI[2nd] & 35S & PLD-int2 & & GUS & Nos & 110 \\
pBI[1st/2nd] & 35S & PLD-int1 & PLD-int2 & GUS & Nos & $82.5(0.72)$ \\
\hline
\end{tabular}


so far having short spacer sequences ( 31 - 85 bases) in-between were able to synergistically up-regulate gene expression in at least one combination of promoters, structural genes, and plant species. Therefore, it is possible that combinations of introns, especially introns separated by short sequences, play important regulatory roles in plants. The introduction of an intact genomic fragment that contained maize phosphoenolpyruvate carboxylase (PEPC) gene into rice resulted in a high expression level and that it was likely that the presence of introns contributed to the high expression level $(\mathrm{Ku}$ et al., 1999). The maize gene for PEPC contains 9 introns. Three of the exons are very short (around or less than a hundred bases), and the introns adjacent to those exons are closely located to each other. Some of these combinations might contributed to the high-level expression. Many plant genes have introns, which are separated only by short exons like the ones in the PEPC gene. For example, 5 out of 8 exons of a maize gene for alcohol dehydrogenase fall within a size of 47-94 bases (Osterman and Dennis, 1989). In a maize gene for triosephosphate isomerase, 5 out of 7 exons fall within a size of 76- 95 bases (Marchionni and Gilbert, 1986). Studies of these introns will certainly provide further insights into regulatory roles of combinations of introns. Our results may suggest that the possible cooperation of introns to achieve higher and/or complicated expression that cannot be conducted with a single intron is present and that the cooperation plays a role in the regulation of gene expression in plant cells.

Several lines of evidence indicate that introns act post-transcriptionally (Callis et al., 1987; Huang and Gorman, 1990; Mascarenhas et al., 1990; Clancy et al., 1994; Donath et al., 1995; Rose and Beliakoff, 2000), however, molecular mechanisms of gene-expression enhancement is not well understood. Since various kinds of factors including unidentified ones appear to be involved in the post transcriptional processes such as capping, transcript elongation, polyadenylation and export of mRNA coupled with pre-mRNA splicing (Simpson and Filipowicz, 1996; Reed and Hurt, 2002; Brown et al., 2003), the difference in enhancement might be the reflection of the difference in type and/or amount of those factors that bind to an intron and adjacent exon sequences. If the transcript including two introns could recruit more factors in type and/or amount than that including a single intron, a synergistic or suppressive effect might occur depending on those factors, possibly through the interaction between those factors. In our study, the same constructs with two introns had different effects de- pending on the cell state. The enhancement observed with pUQ[PLD/Ubi] was less than that with pUQ[Ubi] in maize yellow cells, but was synergistic in greening cells (Table 1). Similar cases were also observed with $\mathrm{pDK}$ [PLD/Cat] between white and green cells of tobacco and with pIG[Ubi/Cat] between white and greening cells of rice (Ueki et al., 1999). These results may indicate the presence of factors that reflect cell state and affect the enhancement by two introns.

The present results indicate that insertion of two introns between a promoter and a transgene is a useful tool for obtaining high expression of the transgene in genetic engineering in higher plants, especially in monocotyledonous plants including rice and maize. The production and analysis of stably-transformed plants are underway.

\section{Acknowledgements}

The authors thank Prof. K. Nakamura of Nagoya University and Prof. K. Wada of Kanazawa University for their helpful advice. The authors also thank S. Yamada and S. Ohta for their help with transient assays, and Y. Amma and M. Tabayashi for technical assistance.

\section{References}

Brown, J. W., Echeverria, M., Qu, L. H., 2003. Plant snoRNAs: functional evolution and new modes of gene expression. Trends Plant Sci., 8: 42-49.

Callis, J., Fromm, M., Walbot, V., 1987. Introns increase gene expression in cultured maize cells. Genes Dev., 1: 1183-1200.

Christensen, A. H., Sharrock, R. A., Quail, P. H., 1992. Maize polyubiquitin genes: structure, thermal perturbation of expression and transcript splicing, and promoter activity following transfer to protoplasts by electroporation. Plant Mol. Biol., 18: 675-689.

Clancy, M., Vasil, V., Hannah, C., Vasil, I. K., 1994. Maize Shrunken-1 intron and exon regions increase gene expression in maize protoplasts. Plant Sci., 98: 151161.

Curie, C., Axelos, M., Bardet, C., Atanassova, R., Chaubet, N., Lescure, B., 1993. Modular organization and development activity of an Arabidopsis thaliana EF-1 $\alpha$ gene promoter. Mol. Gen. Genet., 238: 428-436.

Dean, C., Favreau, M., Bond-Nutter, D., Bedbrook, J., Dunsmuir, P., 1989. Sequences downstream of translation start regulate quantitative expression of two petunia $r b c S$ genes. Plant Cell, 1: 201- 208.

Donath, M., Mendel, R., Cerff, R., Martin, W., 1995. Introndependent transient expression of the maize GapA1 gene. Plant Mol. Biol., 28: 667-676.

Fu, H., Kim, S. Y., Park, W. D., 1995. High-level tuber expression and sucrose inducibility of a potato Sus4 
sucrose synthase gene require $5^{\prime}$ and $3^{\prime}$ flanking sequences and the leader intron. Plant Cell, 7: 13871394.

Huang, M. T., Gorman, C. M., 1990. Intervening sequences increase efficiency of RNA 3 ' processing and accumulation of cytoplasmic RNA. Nucleic Acids Res., 18: 937 -947 .

Jefferson, R. A., 1987. Assaying chimeric genes in plants: The GUS gene fusion system. Plant Mol. Biol. Rep., 5: 387-405.

Jeon, J. S., Lee, S., Jung, K. H., Jun, S. H., Kim, C., An, G., 2000. Tissue- preferential expression of a rice alphatubulin gene, OsTubA1, mediated by the first intron. Plant Physiol., 123: 1005- 1014.

Kovtun, Y., Chiu, W. L., Zeng, W., Sheen, J., 1998. Suppression of auxin signal transduction by a MAPK cascade in higher plants. Nature, 395: 716-720.

Ku, M. S., Agarie, S., Nomura, M., Fukayama, H., Tsuchida, H., Ono, K., Hirose, S., Toki, S., Miyao, M., Matsuoka, M., 1999. High-level expression of maize phosphoenolpyruvate carboxylase in transgenic rice plants. Nat. Biotechnol., 17: 76-80.

Leckie, F., Devoto, A., De Lorenzo, G., 1994. Normalization of GUS by luciferase activity from the same cell extract reduces transformation variability. Biotechniques, 17: 52-53, 56-57.

Luehrsen, K. R., Walbot, V., 1991. Intron enhancement of gene expression and the splicing efficiency of introns in maize cells. Mol. Gen. Genet., 225: 81-93.

Luehrsen, K. R., Walbot, V., 1994. Addition of A- and Urich sequence increases the splicing efficiency of a deleted form of a maize intron. Plant Mol. Biol., 24: $449-463$.

Maas, C., Laufs, J., Grant, S., Korfhage, C., Werr, W., 1991. The combination of a novel stimulatory element in the first exon of the maize Shrunken-1 gene with the following intron 1 enhances reporter gene expression up to 1,000-fold. Plant Mol. Biol., 16: 199- 207.

Marchionni, M., Gilbert, W., 1986. The triosephosphate isomerase gene from maize: introns antedate the plantanimal divergence. Cell, 46: 133-141.

Maruta, Y., Ueki, J., Saito, H., Nitta, N., Imaseki, H., 2001. Transgenic rice with reduced glutelin content by transformation with glutelin A antisense gene. Mol. Breed., 8: $273-284$.

Mascarenhas, D., Mettler, I. J., Pierce, D. A., Lowe, H. W., 1990. Intron-mediated enhancement of heterologous gene expression in maize. Plant Mol. Biol., 15: $913-$ 920.

McElroy, D., Zhang, W., Cao, J., Wu, R., 1990. Isolation of an efficient actin promoter for use in rice transformation. Plant Cell, 2: 163-171.

Morioka, S., Ueki, J., Komari, T., 1997. Characterization of two distinctive genomic clones (accession Nos. $\mathrm{AB} 001919$ and $\mathrm{AB} 001920$ ) for phospholipase D from rice (PGR97-076). Plant Physiol., 114: 396.

Norris, S. R., Meyer, S. E., Callis, J., 1993. The intron of Arabidopsis thaliana polyubiquitin genes is conserved in location and is a quantitative determinant of chimeric gene expression. Plant Mol. Biol., 21: 895-906.

Ohta, S., Mita, S., Hattori, T., Nakamura, K., 1990. Construction and expression in tobacco of a $\beta$-glucuronidase (GUS) reporter gene containing an intron within the coding sequence. Plant Cell Physiol., 31: 805-813.

Osterman, J. C., Dennis, E. S., 1989. Molecular analysis of the $A D H I-C m$ allele of maize. Plant Mol. Biol., 13: 203-212.

Ow, D. W., Wood, K. V., Deluca, M., De Wet, J. R., Helinski, D. R., Howell, S. H., 1986. Transient and stable expression of the firefly luciferase gene in plant cells and transgenic plants. Science, 234: 856-859.

Reed, R., Hurt, E., 2002. A conserved mRNA export machinery coupled to pre-mRNA splicing. Cell, 108: $523-531$.

Rethmeier, N., Seurinck, J., Van Montagu, M., Cornelissen, M., 1997. Intron-mediated enhancement of transgene expression in maize is a nuclear, gene-dependent process. Plant J., 12: $895-899$.

Rose, A. B., Beliakoff, J. A., 2000. Intron-mediated enhancement of gene expression independent of unique intron sequences and splicing. Plant Physiol., 122: 535542.

Rose, A. B., Last, R. L,, 1997. Introns act post-transcriptionally to increase expression of the Arabidopsis thaliana tryptophan pathway gene PAT1. Plant J., 11: 455464.

Sambrook, J., Fritsch, E. F., Maniatis, T., 1989. Molecular Cloning. Cold Spring Harbor Laboratory Press, Plainview, New York.

Sheen, J., 1991. Molecular mechanisms underlying the differential expression of maize pyruvate, orthophosphate dikinase genes. Plant Cell, 3: 225-245.

Simpson, G. G., Filipowicz, W., 1996. Splicing of precursors to mRNA in higher plants: mechanism, regulation and sub-nuclear organisation of the spliceosomal machinery. Plant Mol. Biol., 32: 1-41.

Tanaka, A., Mita, S., Ohta, S., Kyozuka, J., Shimamoto, K., Nakamura, K., 1990. Enhancement of foreign gene expression by a dicot intron in rice but not in tobacco is correlated with an increased level of mRNA and an efficient splicing of the intron. Nucleic Acids Res., 18: $6767-6770$.

Ueki, J., Ohta, S., Morioka, S., Komari, T., Kuwata, S., Kubo, T., Imaseki, H., 1999. The synergistic effects of two-intron insertions on heterologous gene expression and advantages of the first intron of a rice gene for phospholipase D. Plant Cell Physiol., 40: 618-623.

Vasil, V., Clancy, M., Ferl, R. J., Vasil, K. I, Hannah, L. C., 1989. Increased gene expression by the first intron of maize shrunken-1 locus in grass species. Plant 
Physiol., 91: 1575-1579.

Xu, Y., Yu, H., Hall, T. C., 1994. Rice triosephosphate isomerase gene $5^{\prime}$ sequence directs $\beta$-glucuronidase activity in transgenic tobacco but requires an intron for expression in rice. Plant Physiol., 106: 459-467.
Zhang, S. H., Lawton, M. A., Hunter, T., Lamb, C. J., 1994. atpk1, a novel ribosomal protein kinase gene from Arabidopsis. I. Isolation, characterization, and expression. J. Biol. Chem., 269: 17586-17592. 